\title{
Monitoring Viscoelastic Blood Properties during Pediatric Cardiac Surgery: The Challenge of Data Driven Hemostasis
}

\author{
Zhe Amy Fang', Meena Nathan ${ }^{2}$, Sirisha Emani ${ }^{2}$, Sitaram Emani ${ }^{2}$, Juan C. Ibla ${ }^{3 *}$ \\ 'Department of Anesthesia and Pain Medicine, Hospital for Sick Children, Toronto, Ontario, Canada \\ ${ }^{2}$ Department of Cardiac Surgery, Boston Children's Hospital and Harvard Medical School, Boston, MA, USA \\ ${ }^{3}$ Division of Cardiac Anesthesia, Department of Anesthesiology, Critical Care and Pain Medicine, Boston Children's Hospital, Harvard Medical School, Boston,
} MA, USA

Article Info

\section{Article Notes}

Received: June 14, 2020

Accepted: July 15, 2020

\section{*Correspondence:}

Dr. Juan C. Ibla, Division of Cardiac Anesthesia, Department of Anesthesiology, Perioperative and Pain Medicine, Boston Children's Hospital,300 Longwood Avenue, Boston, MA, 02115, USA; Telephone No: (617)355-6225;

Email: juan.ibla@childrens.harvard.edu.

(c) $2020 \mathrm{lbla} \mathrm{JC}$. This article is distributed under the terms of the Creative Commons Attribution 4.0 International License.

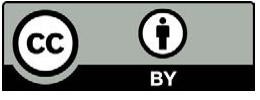

\section{Keywords:}

Pediatric Cardiac Surgery

Congenital Heart Disease

Thromboelastography

Hemostasis

Thrombosis

\section{Abstract}

Thromboelastography, a point of care graphical representation of the activation of coagulation and fibrin polymerization process, assists clinicians in making diagnostic and transfusion-related decisions in the perioperative setting. There is growing interest in applying this technology to pediatric cardiac surgery and this article reviews the currently available evidence for the use of thromboelastography (TEG) and thromboelastometry (ROTEM) in this population. A few studies exist on the use of TEG/ROTEM to accurately guide transfusion and positively impacting patient outcomes, indicating a need for additional studies to validate its utility during pediatric cardiac surgery.

\section{Introduction}

Thromboelastography provides a graphical representation of the activation of coagulation and fibrin polymerization process and was first described by Hartert in $1948^{1}$. It is a point of care test used to assess the viscoelastic properties of whole blood during the active process of coagulation. Technically, thromboelastography (TEG) consists of a pin that is suspended in a cup containing a whole blood sample as it undergoes clot formation. As the clot strengthens, the elastic properties in the sample change, increasing the torque between the pin and the cup and graphically presenting a typical thromboelastograph. In the case of rotational thromboelastometry (ROTEM), the pin rotates in the fixed cup and the change in torque is detected optically and graphically presented ${ }^{2}$. Depending on the particular system, an activator of coagulation may be used, such as celite, kaolin, or tissue factor ${ }^{2}$. Kaolin activated TEG provides information similar to partial thromboplastin time, while tissue factor is commonly used for the EXTEM portion of ROTEM, which approximates prothrombin time ${ }^{3}$. The combination of tissue factor and kaolin approximates the measurement of activated clotting time and is the basis for Rapid TEG ${ }^{3}$. Figure 1 provides a sample TEG tracing and Table 1 provides both TEG and ROTEM parameters and the significance of the measurement.

The clinical value of TEG and ROTEM testing relies on the ability to evaluate coagulation as a continuum from activation to fibrin formation and also measure platelet contribution to clot formation. Given these advantages, there has been increased interest in incorporating TEG and ROTEM testing in pediatric cardiac surgery patients to detect defects in coagulation and guide transfusion. This review will discuss the role of TEG and ROTEM in pediatric patients, 


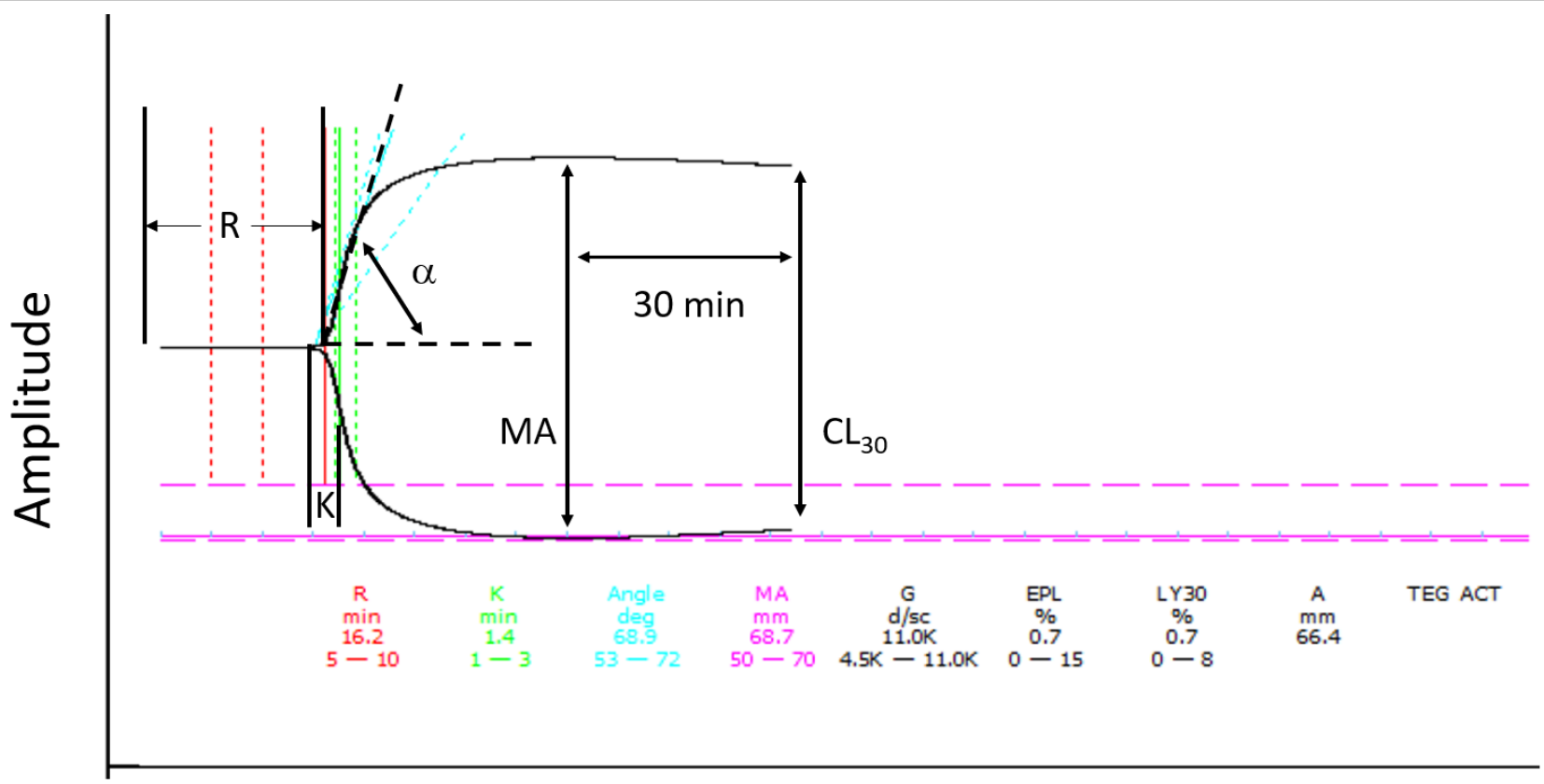

\section{Time}

R: R time; K: K time; $\alpha$ : alpha angle; MA: maximum amplitude; CY30: clot lysis after 30 min

Figure 1: Sample TEG Tracing

Table 1. TEG and ROTEM parameters

\begin{tabular}{|l|c|c|c|}
\hline \multicolumn{1}{|c|}{ Instrumentation } & TEG & ROTEM & Measurement \\
\hline Period to $2 \mathrm{~mm}$ amplitude & $\mathrm{R}$ & $\mathrm{CT}$ & Alterations of coagulation factors \\
\hline Period from 2 to $20 \mathrm{~mm}$ amplitude & $\mathrm{K}$ & $\mathrm{CFT}$ & Alterations in platelet count/function, and/or fibrinogen \\
\hline$\alpha$ angle & $\alpha$ & $\alpha$ & Alterations in fibrinogen \\
\hline Maximum strength & $\mathrm{MA}$ & $\mathrm{MCF}$ & Alterations in platelet count/function, and/or fibrinogen \\
\hline Amplitude & $\mathrm{A} 30, \mathrm{~A} 60$ & $\mathrm{~A} 10, \mathrm{~A} 15, \mathrm{~A} 30$ & \\
\hline Clot lysis after 30 and $60 \mathrm{~min}$ & $\mathrm{CL30}, \mathrm{CL} 60$ & $\mathrm{LY} 30, \mathrm{LY} 60$ & Fibrinolytic enzymes, fibrinolysis inhibitors \\
\hline Time to lysis & $\mathrm{TTL}(2 \mathrm{~mm}$ drop from MA) & $\mathrm{CLT}(10 \%$ from MCF $)$ & Fibrinolytic enzymes, fibrinolysis inhibitors \\
\hline
\end{tabular}

the evidence for its use in pediatric cardiac surgery, and finally the ability for the system to detect potential coagulopathy and thrombotic complications.

\section{Basics of TEG/ROTEM in Pediatrics}

In children, the coagulation system matures as the hepatic synthetic function develops towards adult levels however, vitamin K deficiency, prolongation of prothrombin time (PT) and activated partial thromboplastin time (aPTT) are evident at birth ${ }^{4}$. In neonates, there is a relative deficiency of vitamin $\mathrm{K}$ dependent factors, but factor VIII, and von Willebrand factor are elevated, and platelet function is activated providing a physiologic balance preventing neonates from bleeding excessively ${ }^{4}$. How do these developmental features affect TEG/ROTEM parameters in neonates and children? Different groups of investigators have studied normal reference ranges for TEG in pediatric populations of different ages groups ${ }^{5-9}$. ROTEM reference ranges have been published for adults based on multicenter center investigations, similar pediatrics studies have not been completed ${ }^{10}$.
Studies using kaolin as the activator found variable results comparing pediatric values to adult reference ranges. Mirabella et al and Chan, et.al., found no difference between pediatric patients from newborns to age 16 and adult TEG parameters ${ }^{5,6}$. While Edwards et.al., found that neonates at day 0 of life had a shorter $\mathrm{R}$ time, a wider alpha angle, and maximum amplitude (MA) compared to children aged $6.5 \pm 4.8$ years of age ${ }^{7}$. Compared to adults, neonates demonstrated a shorter $\mathrm{R}$ time, but no differences in alpha angle and maximum amplitude were identified ${ }^{7}$. Pivalizza studied Celite activated TEG in healthy children and found that the alpha angle was wider and fibrinolysis was elevated in patients less than 24 months of age ${ }^{8}$. Miller and colleagues did not use activators, and found that children under 1 year of age had shorter $\mathrm{R}$ and $\mathrm{K}$ time, and wider angle ${ }^{9}$. In addition, Kim and colleagues specifically studied the ROTEM reference values for pediatric patients of different age groups up to the age of 16 years with congenital heart disease $\mathrm{e}^{11}$. They demonstrated that the EXTEM in patients less than 3 months of age had shorter clotting 
time (CT), clot formation time (CFT), steeper alpha angle, and greater maximum clot firmness (MCF) and amplitude at $10 \mathrm{~min}$ (A10). The INTEM demonstrated a significantly longer CT in early infancy. The investigators also separated patients based on cyanotic or non-cyanotic heart disease ${ }^{11}$. Cyanotic patients demonstrated significantly prolonged CT, CFT, reduced alpha angle, A10, and MCF. Given the lack of consensus in the reports, interpretation of TEG and ROTEM in the pediatric population must be approached with caution and based on the experience of individual institutions on specific populations. An example of a TEG tracing is shown in Figure 1. Individual characteristics of the TEG measurement represent a specific component of the coagulation system. Table 1 shows individual TEG parameters and their corresponding ROTEM values.

\section{Role of TEG/ROTEM in Hemostasis}

Transfusion is associated with complications and increased morbidity and mortality ${ }^{12-14}$. Traditionally, in cardiac surgery, the decision to transfuse is frequently based on clinical judgment rather than coagulation parameters. However recently, there have been increased interest in using evidence-based techniques to determine the need for transfusion and TEG and ROTEM has been proposed as a point of care tests that may be used to guide transfusion. TEG /ROTEM may be helpful as a part of a transfusion algorithm, or it may be used to determine early coagulopathy, or incomplete heparin reversal ${ }^{15-18}$.

In the adult cardiac surgery and trauma literature, there is evidence to support the use of TEG and ROTEM based transfusion algorithms to guide transfusion. Gonzalez et.al., studied the use of TEG guided resuscitation versus conventional coagulation assays in adult trauma patients using a randomized controlled trial and found that TEG guided trauma resuscitation was associated with decreased mortality and less transfusion ${ }^{19}$. A recent Cochrane review published in 2016 found weak evidence in support for the use of TEG or ROTEM for elective cardiac surgery in a predominantly adult population, with reduced mortality and reduced red blood cell and platelet transfusion ${ }^{20}$.

There is limited evidence in the pediatric population, and specifically pediatric cardiac surgical population that guided transfusion is associated with improved outcomes. Romlin and colleagues found intraoperative ROTEM use was associated with less transfusion of red blood cell (RBC) and fresh frozen plasma (FFP), but more platelets and cryoprecipitate in pediatric patients undergoing cardiac surgery in a prospective cohort study compared to historical controls $^{21}$. The same group of investigators studied ROTEM at different time points intra-operatively to determine if the technique can be used to detect early coagulopathy ${ }^{22}$. The authors found hemoconcentration and weaning from CPB had limited effect on ROTEM, and thus intraoperative
ROTEM results may be used to guide transfusion and detect early coagulopathy. Nakayama et.al., studied a ROTEM guided transfusion algorithm in pediatric cardiac surgery in a randomized controlled study and found that ROTEM guided transfusion therapy reduced blood loss, RBC transfusion and intensive care unit (ICU) length of stay ${ }^{23}$. Another small prospective study involving 31 children, Cui and colleagues found that while using an intraoperative TEG based transfusion algorithm had no effect on transfusion in the operating room, it did decrease transfusion of FFP in the ICU and ICU length of stay ${ }^{24}$. In a retrospective case control study compared to historical controls, Kane and colleagues found that intraoperative TEG was associated with reduced platelet and cryoprecipitate transfusion without an increase in postoperative complications ${ }^{25}$. Postoperatively for pediatric patients who have undergone cardiac surgery, TEG analysis in the intensive care unit was not found to be superior compared to conventional coagulation parameters in predicting bleeding for the first 4 hours ${ }^{26}$. Pekelharing et al, found the best predictor of bleeding was fibrinogen concentration ${ }^{26}$. In a separate study, Tirotta and colleagues found good correlation between ROTEM FIBTEM maximum clot firmness and fibrinogen concentration, which could potentially be used as an alternative to fibrinogen concentration ${ }^{27}$.

In addition to using TEG and ROTEM as a part of a transfusion algorithm, there has been interest in using this technology as a method for early detection of coagulopathy during cardiac surgery. Emani and colleagues found that in pediatric cardiac surgery patients, those with a TEG MA of less than $45 \mathrm{~mm}$ were more likely to received extended transfusion or surgical re-exploration ${ }^{28}$. In this study, intraoperative transfusion of platelets was demonstrated to mitigate the risk of bleeding. Faraoni et al studied ROTEM parameters and their relation to FFP transfusion ${ }^{29}$. The authors found that the clot formation velocities, as represented by clot amplitude measured at different time points, were significantly increased in patients who received FFP post-operatively, and these parameters were a better predictor in requiring hemostatic products. Moganasundram et.al., studied TEG in pediatric cardiac surgery patients at eight different time points intraoperatively and post-operatively and its association with bleeding ${ }^{30}$. The authors found that hypofibrinogenemia was associated with bleeding and the majority of TEG parameters showed derangement. The author proposes the usage of TEG to determine coagulopathy and predict bleeding.

Incomplete heparin reversal is an additional cause for bleeding during cardiac surgery. Investigators have studied whether TEG can be used to determine residual heparin effects. Magunia, et al, studied the correlation between TEG, activated clotting time (ACT), anti-Xa, 
Table 2. Summary of Studies

\begin{tabular}{|c|c|c|c|c|}
\hline Study & Assay Used & $\begin{array}{c}\text { Number and Age/ } \\
\text { Characteristics of } \\
\text { Patients }\end{array}$ & Description & Findings \\
\hline Emani, et $\mathrm{al}^{28}$ & TEG & $\begin{array}{l}511 ; \text { aged less than } 18 \\
\text { years }\end{array}$ & $\begin{array}{l}\text { TEG was measured after heparin } \\
\text { reversal and on ICU arrival, and the } \\
\text { relationship with the need for surgical } \\
\text { re-exploration and extended transfu- } \\
\text { sion was assessed }\end{array}$ & $\begin{array}{l}\text { Intraoperative TEG MA of less than } 45 \mathrm{~mm} \\
\text { was associated with bleeding. }\end{array}$ \\
\hline Faraoni, et al ${ }^{29}$ & ROTEM & $\begin{array}{l}\text { 49; aged less than } 3 \\
\text { months }\end{array}$ & $\begin{array}{l}\text { ROTEM was performed } 10 \text { minutes } \\
\text { after protamine. The dynamic ROTEM } \\
\text { parameters were used to predict those } \\
\text { who required FFP transfusion postop- } \\
\text { eratively }\end{array}$ & $\begin{array}{l}\text { Total thrombus formation and the maxi- } \\
\text { mal rate of thrombus formation was high- } \\
\text { er in those who received FFP in the CPB } \\
\text { prime. CT, MCF, total thrombus formation, } \\
\text { and maximal rate of thrombus formation } \\
\text { predicted postoperative FFP transfusion. }\end{array}$ \\
\hline $\begin{array}{l}\text { Moganasundram, } \\
\text { et } \mathrm{al}^{30}\end{array}$ & TEG & $\begin{array}{l}50 ; \text { weight less than } \\
20 \mathrm{~kg}\end{array}$ & $\begin{array}{l}\text { TEG and conventional hemostatic vari- } \\
\text { ables were measured at } 8 \text { time points } \\
\text { and their correlation was evaluated. }\end{array}$ & $\begin{array}{l}\text { Hypofibrinogenemia and inadequate } \\
\text { heparin reversal were } 2 \text { factors contribut- } \\
\text { ing to bleeding. TEG parameters showed } \\
\text { derangements. The strongest relationship } \\
\text { was between MA and platelet-fibrinogen } \\
\text { product. }\end{array}$ \\
\hline Magunia, et al ${ }^{31}$ & TEG & 40 ; aged 0 to 4 years & $\begin{array}{l}\text { TEG derived parameters including CK/ } \\
\text { CKH R-time ratio, ACT, anti-Xa and PTT } \\
\text { levels were compared with each other }\end{array}$ & $\begin{array}{l}\text { No correlation between conventional } \\
\text { coagulation tests and TEG-derived results }\end{array}$ \\
\hline Willem, et $\mathrm{al}^{32}$ & ROTEM & $\begin{array}{l}173 ; \text { aged } 0 \text { to } 16 \\
\text { years }\end{array}$ & $\begin{array}{l}\text { After heparin neutralization with } \\
\text { protamine, the ratio between ACT and } \\
\text { the CT measured with INTEM/HEPTEM } \\
\text { were evaluated to determine agree- } \\
\text { ment }\end{array}$ & $\begin{array}{l}\text { ACT and INTEM/HEPTEM CT ratios are } \\
\text { not interchangeable to evaluate heparin } \\
\text { reversal }\end{array}$ \\
\hline
\end{tabular}

and partial thromboplastin time (PTT) in an attempt to determine if TEG can be used to detect residual heparin after protamine reversal ${ }^{31}$. The investigators were not able to find correlations between TEG parameters and anti-Xa levels, and only found weak relationships between $\mathrm{R}$ time, ACT and PTT values. Willem and colleagues also studied whether ACT and ROTEM were interchangeable in measuring residual heparin effects, and found that the two tests are not exchangeable, and clinical correlations were required ${ }^{32}$. Overall, the limited evidence suggests that TEG and ROTEM may not be a good tool for detecting incomplete heparin reversal and cannot replace the current standard. See Table 2 for a summary of the studies described.

\section{Can TEG/ROTEM detect Thrombosis in Children?}

In addition to bleeding, thrombosis is also a significant cause of morbidity in the pediatric cardiac population. TEG and ROTEM can also be used to detect hypercoagulable states. There is increasing interest in using TEG to detect those at increased risk and those who have already developed thrombosis.

In a recently published systematic review and meta-analysis studying TEG and its ability to detect hypercoagulable states in the perioperative and trauma setting, the authors found that only the MA is consistently used to define hypercoagulability, and be predictive of
$\mathrm{VTE}^{33}$. The authors included five studies for the metaanalysis and found that an MA of greater than $65 \mathrm{~mm}$ had an odds ratio of 1.31 (95\% CI 0.74-2.34) of developing VTE. The definition of hypercoagulable state is highly variable making it difficult to use as a predictor. Hincker et.al., used preoperative ROTEM to detect those at increased risk for postoperative thromboembolic complications in adults who underwent major non-cardiac surgery ${ }^{34}$. The authors found that preoperative EXTEM and INTEM in those who developed thromboembolic complications had lower CFT, higher $\alpha$ angle, and higher MCF. The INTEM CFT at $10 \mathrm{~min}$ was the best predictor with a ROC area under the curve of 0.751 . Specifically, in the pediatric population, Henderson et al studied TEG parameters and the thrombotic complications in the pediatric patients on extracorporeal membranous oxygenation ${ }^{35}$. They found that anti-Xa levels (OR 0.62, 95\% CI 0.53-0.72, p <0.001), and TEG R time (OR 1.19, 95\% C 1.07-1.34, p = 0.003) were significantly associated with thrombotic events; however, neither measures showed good discrimination for predicting a bleeding event. The authors suggested targeting an anti-Xa activity of 0.25 units, and an R time of greater than 17.85 minutes to minimize the risk of thrombosis on ECMO patients.

\section{Conclusion}

TEG and ROTEM as a technology show great promise for 
use in the perioperative management of pediatric cardiac surgery patients. It can potentially provide a basis for use as a component of evidence-based transfusion strategy and early detection of coagulopathy, prior to separation from CPB. It may also be used to detect and predict those are high risk for thrombotic complications and prevent over transfusion. Despite its potential, the field lacks rigorous trials examining outcomes in pediatric cardiac surgery. Some of the issues lie in the diversity of transfusion, perfusion, and surgical practices between centers with different case volumes. High quality, multicenter trials in the use of TEG or ROTEM are needed and can potentially revolutionize and unify transfusion practices in pediatric cardiac surgery.

\section{References}

1. Luddington RJ. Thrombelastography/thromboelastometry. Clin Lab Haematol. 2005 Apr; 27(2): 81-90.

2. Bolliger D, Seeberger MD, Tanaka KA. Principles and practice of thromboelastography in clinical coagulation management and transfusion practice. Transfus Med Rev. 2012 Jan; 26(1): 1-13.

3. Whiting D, DiNardo JA. TEG and ROTEM: technology and clinical applications. Am J Hematol. 2014 Feb; 89(2): 228-32.

4. Coté CJ, Lerman J, Anderson BJ, editors. A practice of anesthesia for infants and children. Sixth edition. Philadelphia PA Elsevier 2019.

5. Mirabella L, Cotoia A, Colacicco G, et al. Reference values for coagulation assessment in full-term newborns. Minerva Anestesiol. 2017 Apr; 83(4): 369-74.

6. Chan KL, Summerhayes RG, Ignjatovic V, et al. Reference values for kaolin-activated thromboelastography in healthy children. Anesth Analg. 2007 Dec; 105(6): 1610-3, table of contents.

7. Edwards RM, Naik-Mathuria BJ, Gay AN, et al. Parameters of thromboelastography in healthy newborns. Am J Clin Pathol. 2008 Jul; 130(1): 99-102.

8. Pivalizza EG, Pivalizza PJ, Gottschalk LI, et al. Celite-activated thrombelastography in children. J Clin Anesth. 2001 Feb; 13(1): 20-3.

9. Miller BE, Bailey JM, Mancuso TJ, Wet al. Functional maturity of the coagulation system in children: an evaluation using thrombelastography. Anesth Analg. 1997 Apr; 84(4): 745-8.

10. Lang T, Bauters A, Braun SL, et al. Multi-centre investigation on reference ranges for ROTEM thromboelastometry. Blood Coagul Fibrinolysis Int J Haemost Thromb. 2005 Jun; 16(4): 301-10.

11. Kim JY, Shin YR, Kil HK, et al. Reference Intervals of Thromboelastometric Evaluation of Coagulation in Pediatric Patients with Congenital Heart Diseases: A Retrospective Investigation. Med Sci Monit Int Med J Exp Clin Res. 2016 Oct 6; 22: 3576-87.

12. Goobie SM, Haas T. Perioperative bleeding management in pediatric patients. Curr Opin Anaesthesiol. 2016 Jun; 29(3): 352-8.

13. LaPar DJ, Crosby IK, Ailawadi G, et al. Blood product conservation is associated with improved outcomes and reduced costs after cardiac surgery. J Thorac Cardiovasc Surg. 2013 Mar; 145(3): 796-803; discussion 803-804.

14. Khan JH, Green EA, Chang J, et al. Blood and Blood Product Conservation: Results of Strategies to Improve Clinical Outcomes in Open Heart Surgery Patients at a Tertiary Hospital. J Extra Corpor Technol. 2017; 49(4): 273-82.

15. Li C, Zhao Q Yang K, et al. Thromboelastography or rotational thromboelastometry for bleeding management in adults undergoing cardiac surgery: a systematic review with meta-analysis and trial sequential analysis. J Thorac Dis. 2019 Apr; 11(4): 1170-81.

16. Serraino GF, Murphy GJ. Routine use of viscoelastic blood tests for diagnosis and treatment of coagulopathic bleeding in cardiac surgery: updated systematic review and meta-analysis. Br J Anaesth. 2017 01; 118(6): 823-33.

17. Rigouzzo A, Louvet N, Favier R, et al. Assessment of Coagulation by Thromboelastography During Ongoing Postpartum Hemorrhage: A Retrospective Cohort Analysis. Anesth Analg. 2020; 130(2): 416-25.

18. Brill JB, Badiee J, Zander $\mathrm{AL}$, et al. The rate of deep vein thrombosis doubles in trauma patients with hypercoagulable thromboelastography. J Trauma Acute Care Surg. 2017; 83(3): 413-9.

19. Gonzalez E, Moore EE, Moore HB, et al. Goal-directed Hemostatic Resuscitation of Trauma-induced Coagulopathy: A Pragmatic Randomized Clinical Trial Comparing a Viscoelastic Assay to Conventional Coagulation Assays. Ann Surg. 2016 Jun; 263(6): 10519.

20. Wikkelsø A, Wetterslev J, Møller AM, et al. Thromboelastography (TEG) or rotational thromboelastometry (ROTEM) to monitor haemostatic treatment in bleeding patients: a systematic review with meta-analysis and trial sequential analysis. Anaesthesia. 2017 Apr; 72(4): 519-31.

21. Romlin BS, Wahlander $\mathrm{H}$, Berggren $\mathrm{H}$, et al. Intraoperative thromboelastometry is associated with reduced transfusion prevalence in pediatric cardiac surgery. Anesth Analg. 2011 Jan; 112(1): 30-6.

22. Romlin BS, Wahlander H, Synnergren M, et al. Earlier detection of coagulopathy with thromboelastometry during pediatric cardiac surgery: a prospective observational study. Paediatr Anaesth. 2013 Mar; 23(3): 222-7.

23. Nakayama Y, Nakajima Y, Tanaka KA, et al. Thromboelastometryguided intraoperative haemostatic management reduces bleeding and red cell transfusion after paediatric cardiac surgery. Br J Anaesth. 2015 Jan; 114(1): 91-102.

24. Cui Y, Hei F, Long $\mathrm{C}$, et al. Perioperative monitoring of thromboelastograph on blood protection and recovery for severely cyanotic patients undergoing complex cardiac surgery. Artif Organs. 2010 Nov; 34(11): 955-60.

25. Kane LC, Woodward CS, Husain SA, et al. Thromboelastography--does it impact blood component transfusion in pediatric heart surgery? J Surg Res. 2016 Jan; 200(1): 21-7.

26. Pekelharing J, Furck A, Banya W, et al. Comparison between thromboelastography and conventional coagulation tests after cardiopulmonary bypass surgery in the paediatric intensive care unit. Int J Lab Hematol. 2014 Aug; 36(4): 465-71.

27. Tirotta CF, Lagueruela RG, Madril D, et al. Correlation Between ROTEM FIBTEM Maximum Clot Firmness and Fibrinogen Levels in Pediatric Cardiac Surgery Patients. Clin Appl Thromb Off J Int Acad Clin Appl Thromb. 2019 Dec; 25: 1076029618816382.

28. Emani S, Sleeper LA, Faraoni D, et al. Thromboelastography Is Associated With Surrogates for Bleeding After Pediatric Cardiac Operations. Ann Thorac Surg. 2018; 106(3): 799-806.

29. Faraoni D, Fenger-Eriksen C, Gillard S, et al. Evaluation of dynamic parameters of thrombus formation measured on whole blood using rotational thromboelastometry in children undergoing cardiac surgery: a descriptive study. Paediatr Anaesth. 2015 Jun; 25(6): 573-

30. Moganasundram S, Hunt BJ, Sykes K, et al. The relationship among thromboelastography, hemostatic variables, and bleeding after cardiopulmonary bypass surgery in children. Anesth Analg. $2010 \mathrm{Apr}$ $1 ; 110(4)$ : 995-1002. 
31. Magunia H, Schenk S, Schlensak C, et al. Detection of early incomplete heparin reversal following congenital cardiac surgery: A single-center retrospective observational study. Thromb Res. 2019 0ct; 182: 33-8.

32. Willems A, Savan V, Faraoni D, et al. Heparin Reversal After Cardiopulmonary Bypass: Are Point-of-Care Coagulation Tests Interchangeable? J Cardiothorac Vasc Anesth. 2016 Oct; 30(5): 1184-9.

33. Wesley B, Matthew L, Michael M, et al. The Ability of Thromboelastography to Detect Hypercoagulability: A Systematic Review \& Meta-Analysis. J Orthop Trauma. 2019 Dec 5.
34. Hincker A, Feit J, Sladen RN, et al. Rotational thromboelastometry predicts thromboembolic complications after major non-cardiac surgery. Crit Care Lond Engl. 2014 Oct 8; 18(5): 549.

35. Henderson N, Sullivan JE, Myers J, et al. Use of Thromboelastography to Predict Thrombotic Complications in Pediatric and Neonatal Extracorporeal Membranous Oxygenation. J Extra Corpor Technol. 2018; 50(3): 149-54. 